\title{
Gritical study of coleoptile elongation controlled by IAA and ABA I. Growth kinetics and distribution
}

\author{
Claude Schlienger, Rose-Marie Hofer and Paul-Emile Pilet \\ Institute of Plant Biology and Physiology, University of Lausanne, 1005 Lausanne, Pl. de la Riponne, \\ Switzerland
}

(Received January 31, 1977)

\begin{abstract}
The elongation rate of wheat coleoptiles, treated with IAA and ABA, was already affected during the first $8 \mathrm{hr}$ of culture. The most sensitive zone of the material-for hormonal treatments-was first localized and then comparatively cultured both in situ and in vitro. Growth stimulation by IAA was nearly proportional to its concentration up to $10^{-4} \mathbf{x}$, while $\mathrm{ABA}$ alwayz induced an significant inhibition.
\end{abstract}

The inhibitory effect of abscisic acid (ABA) on growth is now clearly established (see 15), and its interactions with indolyl-3-acetic acid (IAA) have been studied using several parameters $(21,22,25)$.

It was of interest to analyse the growth pattern of intact coleoptiles treated with IAA and ABA and to compare the results obtained with those given by a usual coleoptile segment test $(14,24)$.

\section{Material and methods}

Caryopses of Triticum vulgare L., cv. Probus were soaked in water for $2 \mathrm{hr}$, carefully washed and sown on moist filter paper, as previously described (7). After $72 \mathrm{hr}$ (dark; $25 \pm 1^{\circ} \mathrm{C}$ ), only seedlings with $20 \pm 1 \mathrm{~mm}$ coleoptiles were selected.

In situ experiments: The surface of the coleoptiles was carefully marked into $1 \mathrm{~mm}$ segments with India ink, and 20 intact seedlings were placed in Petri dishes on moist filter paper for $4 \mathrm{hr}$. Then, after careful washing, they were transferred (zero time) onto active solutions (still on filter paper).

In vitro experiments: According to a usual technique $(17,19)$, coleoptile segments of $5 \mathrm{~mm}$ in length were excised at $5 \mathrm{~mm}$ from the tip. After $4 \mathrm{hr}$ incubation in water (zero time), they were immersed in active solutions.

Active solutions: Phosphate-citrate buffer solutions at $\mathrm{pH} 5.4$ (17) containing $2 \%$ sucrose were used with or without IAA or ABA at several concentrations.

All active solutions and materials (Petri dishes, filters, etc.,) employed were previously sterilized. All manipulations were conducted under dim green light.

Changes of elongation were analyzed using a photographic technique (26). Each result thus represents the mean response of at least 60 measurements. Standard errors of this mean have been calculated and significant differences assessed by the $t$-test.

Abbreviations: IAA, indolyl-9-acetic acid; ABA, abscisic acid. 


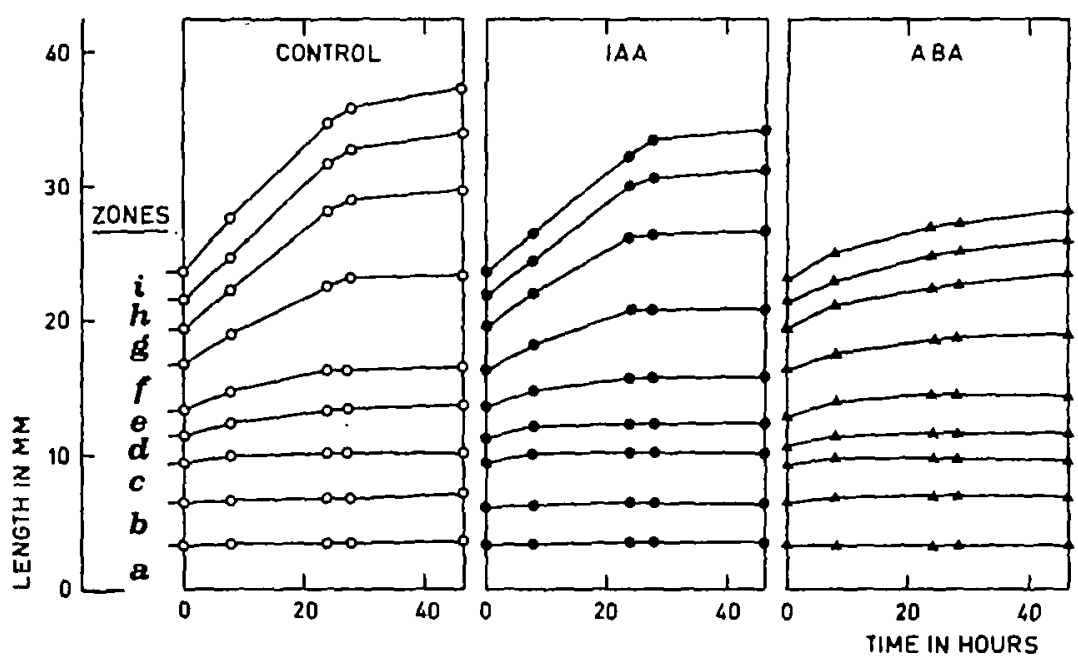

Fig. 1. Comparative alongation in $\%$ for the difforont regions of intact colooptiles, the seedlings being cultured $46 \mathrm{hr}$ on buffer solution (control), with or without $I A A\left(1 \times 10^{-4} \mathrm{w}\right)$ or $A B A\left(3.8 \times 10^{-6} \mathrm{M}\right)$.

\section{Results and discussion}

Two series of results will be successively discussed concerning growth of 1) coleoptiles from intact seedlings and 2) coleoptile segments.

Coleoptiles were marked into 9 zones (a to i). Fig. 1 shows the growth pattern over $46 \mathrm{hr}$ for the most stimulating IAA concentration $\left(10^{-4} \mathrm{M}\right)$ and for an inhibiting $\mathrm{ABA}$ concentration $\left(3.8 \times 10^{-6} \mathrm{M}\right)$. Elongation was found to be significant only for about $24 \mathrm{hr}$. From these data, the growth velocity of each zone was calculated (Table 1): as can be seen, it increased progressively from the base to the apex of the coleoptile (a to $h$ ). Elongation was already affected by IAA and ABA treatments during the first $8 \mathrm{hr}$.

In order to determine the most sensitive zone for such a hormonal treatment,

Table 1 Growth volocity in $\mu \mathrm{m}$ por hour (dering $8 \mathrm{hr}$ ) for sawral regions of colooptiles from intact seedlings in presence or absence of $I A A$ and $A B A$

\begin{tabular}{crrr}
\hline $\begin{array}{c}\text { Regions } \\
\text { (ree Fig. 1) }\end{array}$ & \multicolumn{1}{c}{ Control } & \multicolumn{1}{c}{ IAA } & \multicolumn{1}{c}{ ABA } \\
\hline a & $12.5 \pm 8.5$ & $10.0 \pm 8.2$ & $6.3 \pm 4.6$ \\
b & $51.3 \pm 9.4$ & $22.5 \pm 12.2$ & $17.5 \pm 8.0$ \\
c & $90.0 \pm 15.0$ & $81.3 \pm 22.2$ & $76.3 \pm 26.3$ \\
d & $140.0 \pm 24.6$ & $102.0 \pm 25.6$ & $95.0 \pm 25.1$ \\
e & $202.0 \pm 25.8$ & $162.0 \pm 23.5$ & $142.5 \pm 23.9$ \\
f & $296.3 \pm 40.2$ & $216.3 \pm 27.4$ & $185.0 \pm 39.0$ \\
g & $363.8 \pm 36.5$ & $302.5 \pm 37.6$ & $241.3 \pm 37.2$ \\
h & $412.5 \pm 42.0$ & $346.3 \pm 51.6$ & $248.8 \pm 40.8$ \\
i & $50.3 \pm 5.8$ & $36.3 \pm 5.8$ & $26.3 \pm 3.0$
\end{tabular}

- Most stimulating IAA concentration: $1 \times 10^{-4} \mathrm{u}$.

Inhibiting $A B A$ concentration: $3.8 \times 10^{-6} \mathrm{u}$. 


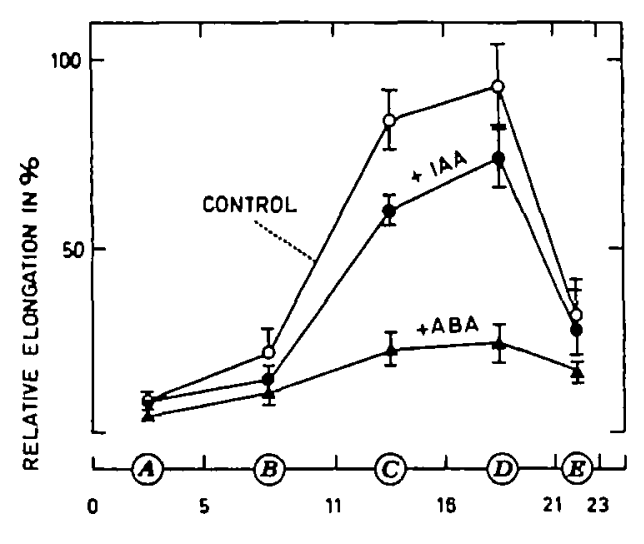

Fig. 2.

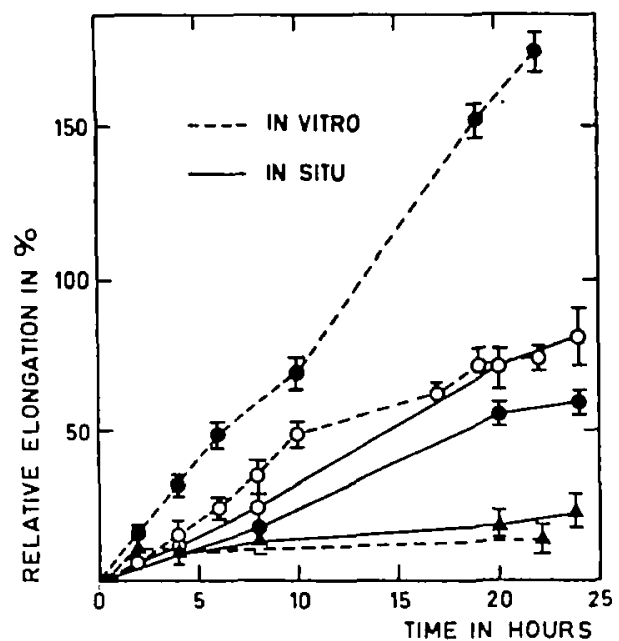

Fig. 3.

Fig. 2. Relative alongation ( \pm slandard error) after 24 hr of intact coleoptiles treated with or without IAA $\left(1 \times 10^{-4}\right.$ M) or $A B A\left(3.8 \times 10^{-6} \mathrm{~m}\right)$. Regions: A $(0-5 \mathrm{~mm}) ; \mathrm{B}(5-11 \mathrm{~mm}) ; \mathrm{C}(11-16 \mathrm{~mm}) ; \mathrm{D}(16-21 \mathrm{~mm})$; E (21-23 mm). Length respectively at $0 \mathrm{hr}\left(\mathrm{L}_{0}\right)$ and at $24 \mathrm{hr}\left(\mathrm{L}_{21}\right)$.

Fig. 3. Comparative alongation ( \pm standard orror) of zone $C(11-16 \mathrm{~mm}$ from the base) for intact colooptiles

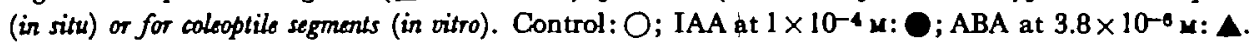

relative elongation (after $24 \mathrm{hr}$ ) of 5 zones (A to E) was measured (Fig. 2). A significant maximum of growth was found in both regions $\mathrm{C}$ and $\mathrm{D}$, as previously reported (18). It was noticed that, for treated coleoptiles, the optimal growth inhibition was also observed in these regions. Under the present conditions, the ABA effect was found to be three times greater than the IAA effect, although the ABA concentration was about twenty five times lower. In the other zones, no significant difference was found for the elongation between treated coleoptiles and the controls.

Relative growth of portion $\mathrm{C}$ (coleoptiles from intact seedlings: in situ) was compared to the elongation of similar segments immersed in the test solution (in vitro). From the results given in Fig. 3, it can be seen that there is no significant difference between either the two controls or the in situ IAA treatment. In contrast, the segments treated in vitro showed a greater "sensitivity" to auxin. The ABA treatment induced a similar inhibition for both segments. Compared to the

Table 2 IAA and ABA effect on relative growth (in situ and in vitro measurements) of coleoptile segments in relation with time

\begin{tabular}{cccccc}
\hline \multirow{2}{*}{ Time in hr } & \multicolumn{2}{c}{ In situ } & & \multicolumn{2}{c}{ In vitro } \\
\cline { 2 - 3 } \cline { 5 - 6 } & IAA & ABA & & IAA & ABA \\
\hline \multirow{2}{*}{4} & $69.6 \pm 7.0$ & $71.3 \pm 6.8$ & & $195.8 \pm 18.5$ & $57.6 \pm 5.1$ \\
& $73.6 \pm 6.2$ & $27.2 \pm 2.9$ & & $251.3 \pm 24.9$ & $19.2 \pm 2.1$
\end{tabular}

Each value is expressed in \% of the control.

Respective IAA and ABA concentrations: $1 \times 10^{-4} \mathrm{x}$ and $3.8 \times 10^{-6} \mathrm{M}$. 


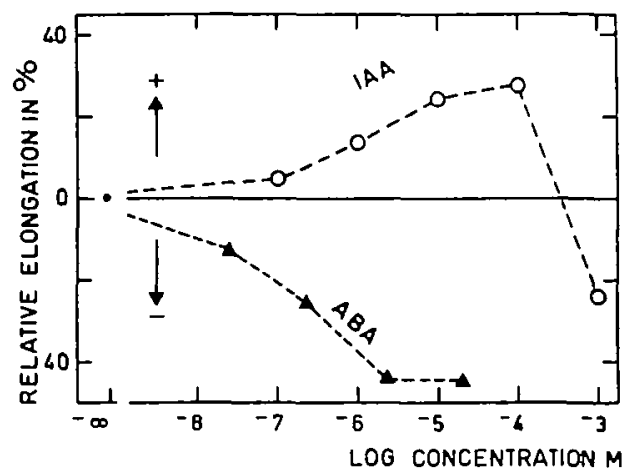

Fig. 4. Relation growoth in \% of calcoptile segments treated with $I A A$ and $A B A$ at different concentrations (from 0 to $10^{-8} \mathbf{y}$ ). Ponitive and negative values show respectively stimulation and inhibition.

control (Table 2), the IAA effect remained quite constant after $4 \mathrm{hr}$ of culture, while the $\mathrm{ABA}$ effect became larger, as incubation time increased.

As previously observed (19), there is a clear correlation between the IAA concentration (in the test solution) and the growth promotion of the coleoptile segments from $10^{-7} \mathrm{M}$ to $10^{-4} \mathrm{M}$ of IAA. In Fig. 4, the results indicate a strong inhibition for a higher concentration $\left(10^{-8} \mathbf{m}\right)$ of IAA. But, under the present conditions, ABA was found to inhibit elongation in every case, and the effect remained unchanged for every concentration tested over $3.8 \times 10^{-6} \mathrm{M}$.

The presence, in intact wheat coleoptiles $(4,18)$ of IAA-oxidases and peroxidases, with a minimal activity in zones $C$ and $D$ (Fig. 2), for which a maximal elongation was reported, may explain, at least partly, the small growth changes (Fig. 1) caused by IAA (treatment in situ). It is well established that the movement of endogenous auxin is basipetal in coleoptiles $(8)$ and acropetal in roots (20), consequently polar $(3,9,11)$. For exogenous IAA, the present data indicated a similar situation (Fig. 3). In fact, IAA applied to the roots showed no significant effect on the elongation of coleoptiles, but, as can be seen in Fig. 3, the in vitro uptake of IAA was linear with time (6). Growth stimulation (Fig. 4) was nearly proportional to the $\log$ of auxin concentration up to $10^{-4} \mathrm{M}(6)$, but a decrease in elongation was observed for a higher concentration of IAA (I).

In contrast, $\mathrm{ABA}$ induced significant growth inhibition in each coleoptile portion, for every tested concentration $(10,16,25)$ for both in vivo and in vitro treatments. The last point could be explained by the fact that ABA is possibly not formed (15) by the coleoptile tissues, which was of course not the case for IAA.

As there exists in coleoptile segments, characterized by the absence of mitosis (2), a proportionality between growth and auxin-induced $\mathrm{H}^{+}$-excretion (5), treatment in vitro either with IAA or acid $\mathrm{pH}$ may have a similar effect on cell wall structure (12), promoting a relase of xyloglucan (13). In contrast, ABA, which may antagonize-at least for the root (23) - any direct or non direct effects on proton extrusion, is known to have a strongly inhibitory effect on increase in the cell volume (26).

\section{References}

( 1 ) Bogie, H. E., G. C. Kreaheck and K. H. Harmet: Calorimetric studies of the elongation of Aorne coleoptile segments. Plant Physiol. 57 : 842-845 (1976).

(2) Böhmer, H.: Untersuchungen uber das Wachstum und den Feinbau der Zellwănde in der Aoma-Kolcoptile. Planta 50: 461-497 (1958). 
(3) Cande, W. Z. and P. M. Ray: Nature of cell-to-cell transfer of auxin in polar transport. ibid. 129: 43-52 (1976).

(4) Chappet, A. et J. Dubouchet: Gradients peroxydariques des coltoptilea de ble. C. R. Acad. Sc. Paris 270: 3224-3227 (1970).

(5) Cleland, R. E.: Furicoccin-induced growth and hydrogen ion excretion of Avene coleoptiles: relation to auxin responses. Planta 128: 201-206 (1976).

(6) Dela Fuente, R. K. and A. C. Leopold: Time course of auxin stimulations of growth. Plant Physiol. 46: 186-189 (1970).

(7) Dubouchet, J.: Variations de croissance et régénération physiologique. Reo. Gén. Bot. 74: $589-611$ (1967).

(8) Gardner, G., S. Shaw and M. B. Willins: LAA transport during the phototropic responses of intact Zoa and Avena coleoptilex. Planta 121:237-251 (1974).

( 9 ) Goldrmith, M. H. M. and P. M. Ray: Intracellular localization of the active proces in polar transport of auxin. ibid. $111: 297-314$ (1973).

(10) Hemberg, T.: Interaction of kinetin and abscisic acid in the Avena staright-growth tert. Phosiol. Plant. 26: 108-109 (1972).

(11) Hertel, R. and R. Flory: Auxin movement in corn coleoptiles. Planta 82: 123-144 (1968).

(12) Hofer, R. M., C. Schlienger and P. E. Pilet: Critical study of coleoptile elongation controlled by IAA and ABA. II. Epidermal surfaces analysed by SEM. Plant \& Cell Physiol. 18: 735-741 (1977).

(13) Jacobs, M. and P. M. Ray: Promotion of xyloglucan metabolism by acid pH. Plant Physiol. 56: 379-376 (1975).

(1f) Kaufman, P. B. and R. A. Jones: Regulation of growth in Awre (oat) stem segments by gibberellic acid and abscisic acid. Physiol. Plant. 91 : $39-43$ (1974).

(15) Milborrow, B. V.: The chemistry and physiology of abscisic acid. Amn. Rev. Plant Physiol. 25: 259-307 (1974).

(16) Muoy, L. T., V. I. Kefeli and R. K. Turetskaya: Correlation between rhythmicality of the growth of wheat coleoptile pieces and their response to natural regulators. Fiziol. Rastenai 20: 1127-1132 (1973).

(17) Nitsch, J. P. and C. Nitsch: Studies on the growth of coleoptile and first internode sections. A new, sensitive, straight-growth test for auxins. Plant Physiol. 31 : 94-111 (1956).

(18) Pilet, P. E. et J. Dubouchet: Gradients auxins-axydasiques des coltoptiles de ble. C. $R$. Acad. Sc. Paris 253: 1846-1848 (1961).

(19) Pilet, P. E. et J. Dubouchet: Proposition d'un test "coltoptile" (Triticum) pour le dosage auxinique. Reo. Gén. Bot. 69: 545-562 (1962).

(20) Pilet, P. E.: Auxin transport in roots: Lens culinaris. Nalure 204: 561-562 (1964).

(21) Pilet, P. E.: The effect of auxin and abscisic acid on the catabolism of RNA. J. Exp. Bot. 21 : 446-451 (1970).

(22) Pilet, P. E.: ABA effects on growth in relation to auxin, RNA and ultrastructure. In Hormonal Regulation in Plant Growth and Deoslopmont. Edited by H. Kaldewey and Y. Vardar. p. 297-315. Verlag Chemie, Weinheim, 1972.

(23) Pilet, P. E.: Control by the root cap on growth and georeaction of roots. In Plant Growth Substances. p. 1104-1110. Hirokawa Publ. Co., Tokyo, 1973.

(2f) Rajagopal, R. and P. Laryen: Auxin balance in the Awena coleoptile. Physiol. Plant. 31 : 119124 (1974).

(25) Rehm, M. M. and M. G. Cline: Rapid growth inhibition of Avene coleoptile segments by abecisic acid. Plant Physiol. 51: 93-96 (1973).

(26) Schlienger, C.: Interactions de l'AIA et de l'ABA sur la croissance et l'ultrastructure des parois cellulaire. Thise en preparation. 